\title{
Trockene Heizungsluft birgt Gefahr - Was Sie Milbenallergikern jetzt raten können
}

\section{Millionen Deutsche leiden an einer Allergie gegen Hausstaub- milben. Gerade jetzt in der kälteren Jahreszeit klagen viele über zunehmende Symptome. Der Ärzteverband Deutscher Allerlogen gibt Tips, wie man die Beschwerden lindern kann.}

$\int$ er steigende Komfort im Wohnbereich, die modernen Zentralheizsysteme und die dicht schlieBenden Fenster haben die Wohnqualität zwar entscheidend verbessert allerdings haben parallel dazu auch die Wohnraumallergene zugenommen. Denn der im Wohnraum allgegenwärtige Hausstaub schafft optimale Lebensbedingungen für Hausstaubmilben. In Schlafmatratzen, Polstermöbeln und Teppichböden fühlen sich Milben wohl.

Hausstaubmilben bevorzugen eine Luftfeuchtigkeit von 65 bis $80 \%$ sowie eine Temperatur von 18 bis $25^{\circ} \mathrm{C}$ und ernähren sich von menschlichen Hautschuppen. Deswegen haben gerade Schlafmatratzen ein ideales Mikroklima für Milben.

Im Sommer nehmen die Milbenpopulationen zu und erreichen ihr Maximum im warmen Spätsommer. Sobald es kalt wird, Fenster geschlossen werden und die Heizperiode beginnt, sterben die Milben aufgrund der trockenen Luft in den Räumen ab. Doch gerade in dieser Zeit erreichen die allergischen Reaktionen ihren Höhepunkt: Denn die allergieauslösenden Exkremente der Milben trocknen aus und bleiben im Hausstaub zurück. Die Heizungsluft wirbelt den Staub auf, die Allergene werden mit der Atemluft inhaliert.

Sensibilisierte Personen reagieren mit Rhinitis, Konjunktivitis oder gar Asthma. J. Sennekamp, Vorstandsmitglied des Ärzteverbandes Deutscher Allergologen. empfiehlt den Betroffenen: „Meiden Sie die Milben, indem Sie die Teppiche entfernen, Matratzen mit einer Schutzhülle überziehen, viel lüften und ein trockenes Milieu besonders im Schlafzimmer schaffen. Wenn die allergischen Symptome, vor allem bei Beschwerden an der Nase und an den Augen, aber auch bei Asthma, trotz dieser Maßnahmen nicht abklingen, dann raten wir zu einer Hyposensibilisierung. Sie erfordert die Mitarbeit des Patienten." Doch die Mühe
$\mathrm{D}$ as ist ein Ergebnis der ersten ostdeutschen Studie, die sich mit der Allergieausprägung bei allergiegefährdeten Neu- und Frühgeborenen durch Umwelteinflüsse befaßt. Das Projekt ergänzt die große „Multizentrische Allergiestudie", die seit einigen Jahren in Westdeutschland läuft.

Ziel des Forscherteams der Sektion Expositionsforschung und Epidemiologie des Umweltforschungszentrums Leipzig-Halle (Ufz), der Leipziger Universitätskinderklinik und des Institutes für Klinische Immunologie und Transfusionsmedizin ist es, die an der Allergieauslösung beteiligten Risikofaktoren zu ermitteln und daraus vorbeugende Maßnahmen abzuleiten.

Dazu werden in regelmäßigen Abständen möglichst bis ins Schulalter al-

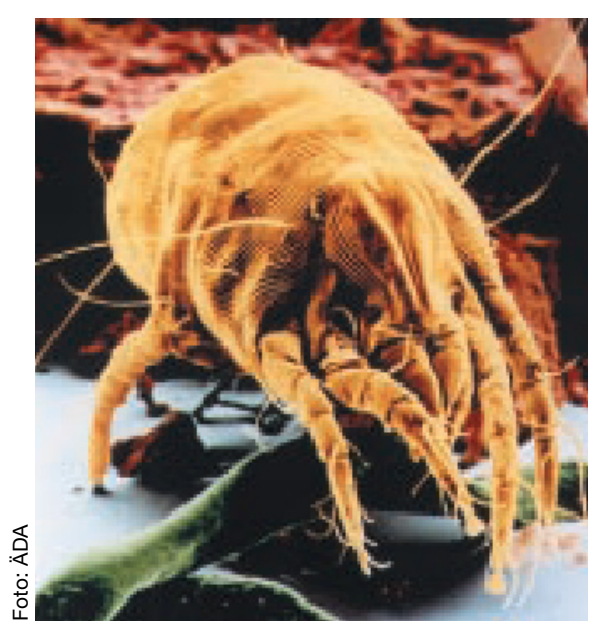

Führend bei der Produktion von Innenraumallergenen: die Hausstaubmilbe.

lohnt sich: Bei 9 von 10 Patienten erzielt diese Behandlung deutliche Besserung.

(red)

\section{Frisch gestrichen - ein weiteres Allergierisiko für Babys?}

\author{
Bei allergiegefährdeten Kindern können sich frisch gestrichene \\ Wände und neu verlegte Fußböden nachteilig auf eine mögliche \\ Allergieentwicklung auswirken.
}

lergiegefährdete Neu- und Frühgeborene der Jahrgänge 1995 bis 1996 untersucht. 436 Kinder wurden in das Programm aufgenommen, davon 117 Frühgeborene. Zur Zeit werden die dreijährigen Kinder und ihre Eltern in die Risikosprechstunde eingeladen. Außer Fragen nach Umweltbelastungen messen die Wissenschaftler Innenraumschadstoffe in Kinderzimmern und nehmen klinische Untersuchungen sowie Allergietests vor.

Bei der Untersuchung im ersten Lebensjahr stellten die Ärzte bei 50 Kindern ein atopisches Ekzem fest. Und ein weiteres Resultat: Neuverlegte Textilbodenbeläge sind häufig mit Atemwegsinfektionen assoziiert.

(red) 